\title{
Plasma Diagnostics for the Compact Ignition Tokamak
}

\author{
S. S. Medley, K. M. Young, and the CIT Diagnostics Team*
}

\author{
Princeson Plasma Physics Laboratory \\ PPPL- -2528 \\ Princeton, New Jersey 08543 \\ DE88 012718
}

\begin{abstract}
The primary mission of the Compact Ignition Tokamak (CIT) is to study the physics of alpha-particle heating in an ignited D-T plasma. $A$ burn ame of about $10 \tau_{\mathrm{E}}$ is projected in a divertor configuration with baseline machine design parameters of $R=2.10 \mathrm{~m}, a=0.65 \mathrm{~m}, b=1.30 \mathrm{~m}, \mathrm{I}_{\mathrm{p}}=11 \mathrm{MA},-\mathrm{T}=10 \mathrm{~T}$ and 10-20 MW of auxiliary RF heating. Plasma temperatures and density are expected to rec. a $\mathrm{T}_{\mathrm{e}}(0)$ $\sim 20 \mathrm{keV}, \mathrm{T}_{\mathrm{j}}(0) \sim 30 \mathrm{keV}$, and $\mathrm{n}_{\mathrm{e}}(0) \sim 1 \times 10^{21} \mathrm{~m}^{-3}$. The combined effects of restricted port access to the plasma, the presence of severe neutron and gamma radiation backgrounds, and the necessity for remote handling of in-cell components create challenging design problems for all of the conventional diagnostics associated with tokamak operations. In addition, new techniques must be developed to diagnose the evolution in space, time, and energy of the confined alpha distribution as well as potential plasma instabilities driven by collective alpha-particle effects. The design effort for CIT diagnostics is presertly in the conceptual phase with activity being focussed on the selection of a viable diagnostic set and the identification of essential research and development projects to support this process. A review of these design issues and other aspects impacting the selection of diagnostic techniques for the CIT experiment will be presented.
\end{abstract}

*Includes Massachusetts Institute of Technology and GA Technologies, Inc.

\section{DISCLAIMER}

\footnotetext{
This report was prepared as an account of work sponsored by an agency of the United States Government. Neither the United States Government nor any agency thereof, nor any of their employees, makes any warranty, express or implied, of assumes any legal liability or responsibility for the accuracy, completeness, or usefulness of any information, apparatus, product, or process disclosed, or represents that its use would not infringe privately owned rights. Reference herein to any specilic commercial product, process, or service by trade name, trademark, manufacturer, or otherwise does not necessarily constitute or imply its endorsement, recommendation, Gr favoring by the United Stales Government or any agency thereof. The views and opinions of authors expressed herein do not necessarily state or reflect those of the United States Government or any agency thereof.
}

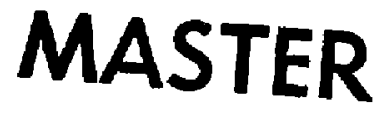

i: :

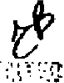




\section{Int roduction}

The mission of the Compact Ignition Tokamak (CIT) is to study the physics of ignited D-T plasmas, that is, plasmas in which a major fraction of the power flow is supplied by alpha-particles generated by D-T fusion reactions. In the contexı of both the U.S. and the international fusion effort, the programmatic role of CIT is to bridge the operating gap between the sub-ignited "breakeven" machines, such as the Tokamak Fusion Test Reactor (TFTR) and the Joint European Torus (JET), and the first-generation fusion power reactor experiments. The near-term study of alpha-particle heating and its effect on confinement is a key issue for future ignited tokamaks. With the provisional exception of $\mathrm{H}$-mode discharges, the energy confinement time in presently operating tokamaks appears to deteriorate as the level of auxiliary heating is increased. If this trend continues with the high levels of alpha-particle hearing needed for an ignited plasma, experimental reactor designs such as ITER will be significantly impacted.

The combination of tight budgets in the U.S. fusion program and realizable engineering technology leads to a CIT ignition device of modest size with high toroidal magnetic field, plasma density, plasma current, and fusion power density. Plasma elongation to maximize the discharge current, auxiliary heating to attain an adequate temperature for ignition, poloidal divenor capability to access improved confinement regimes, and pellet injection to provide particle density and profile control have all been incorporated in the CIT design to enhance the margin for ignition. A brief description of the current CIT machine design and projected plasma parameters is given in Section I.

In the development of tokamak devices, it can be argued that CIT represents the pinnacle of difficulty in diagnostic requirements. Under hostile neutron and gamma radiation conditions, proper diagnosis of ignition behavior demands temporal and spatial measurement not only of the 
conventional plasma parameters but also of the effects of alpha production on plasma heating. confinement, instabiiity phenomena, and so forth. In addition, activation of diagnostic equipment located near the machine due to the radiation fields makes remote maintenance and calibration necessary. These issues and the status of the CIT diagnostic development will be discussed in subsequent sections of this article.

\section{Description of the CIT Machine}

The design of CIT has evolved ${ }^{1}$ during the past two years. One of the major changes has been to increase the size of the machine in order to increase the energy confinement time and, hence, the margin for achieving ignition. Aл elevation view of the cross section of the machine core is shown in Fig. 1 for the present $R=2.10 \mathrm{~m}$ baseline design, which was adopted in March, 1988 . Selected machine and plasma parameters are given in Table I. Several of the CIT design features are worth noting both from the perspective of the machine capability as well as the impact on the implementation of plasma diagnostics.

Compactness is facilitated by a close-fitting vacuum vessel and a poloidal coil system which is primarily external to the toroidal coils. Operation of the field coils at $\mathrm{LN}_{2}$ temperature trires encapsulation of the entire core of the machine inside a cryostat. This creates a deeply reentrant port structure which presents challenges for those diagnostics requiring stable mounting of romponents near the periphery of the plasma. The plasma cross section is elongated in order to maximize the achievable discharge current. A divertor with single- and double-null capability is incorporated to access plasma operation in enhanced confinement regimes.

In order to distribute the wall heat loading in the divertor region over a larger surface area, the strike-point will be swept with a stroke of $-18 \mathrm{~cm}$ during the five-second burn phase of the discharge, using the internal control coil system shown in fig. 1. 
CTT is expected to require $10-20 \mathrm{MW}$ of auxiliary power in order to raise the plasma temperature to ignition levels. On the basis of demonstrated efficient heating, ${ }^{2}$ availability of power in the relevant frequency range, and compatability with the tokamak access, a baseline of $10 \mathrm{MW}$ of ion cyclotron resonance heating (ICRH) power with a design frequency of $95 \mathrm{MHz}$ and a range of 60 - $110 \mathrm{MHz}$ was chosen for $\mathrm{CIT}^{3}$ Plasma heating will be achieved by coupling to the fundamental frequency of a minority ${ }^{3} \mathrm{He}$ species with a transition to the second hamonic of ritium during the igsition phase. Provision exists to incorporate $10 \mathrm{MW}$ or more of additional heating power in the form of either ICRH or electron cycloron resonance heating (ECRH). Compared with ICRH, ECRH offers the potential advantages of significantly higher power density and strongly localized single-pass power deposition, but suitable sources have yet to be developed at $250 \mathrm{GHz}$.

The available run-time at full-field conditions which is projected for the life of the CIT machine is severely restricted by two operational constraints. First, the magnet system is designed for a fatigue lifetime of $\sim 3000$ full-field discharges (including magnet test shots) and $\sim 30,000$ half-stress discharges which correspond to operation at about $70 \%$ of the $10 \mathrm{~T}$ design field. These numbers are to be compared with the 5000-10000 shots per year typical of operations on contemporary tokamaks. Since burning plasma conditions are predicted to be achievable only at substantially full-field and full-current operation, this limited quota of $\sim 3000$ shots means that the CIT diagnostics must be capable not only of measuring all of the necessary parameters on a single-shot basis but also with essentially perfect reliability. A second, practical constraint arises from the time required between shots to re-cool the toroidal and poloidal field coils to $\mathrm{LN}_{2}$ temperature. For discharges at the full field of $10 \mathrm{~T}$ with the nominal five-second flat-top time, the re-cool period is one hour, which implies a maximum of -15 shots per day under ideal operating conditions.

The design and prelininary consuruction phase of CIT is ongoing at the present time with 
first-plasma operation scheduled for the mid-1990's.

\section{CIT Diagnostics Issues and Concerns}

The CIT diagnotics must provide most of the plasma parameter measurements characteristic of tokamaks in operation at the present time with the added capability of diagnosing the collective alpha-particle effects envisioned during the D-T bum phase. These measurements must be made with very restricted access to the tokamak and in the presence of a neutron and gamma radiation background $^{4}$ which is sufficiently high that radiation shielding must be an integral part of any diagnostic concept in order to prevent intolerable noise levels or damage to the components. The radiation background also leads to requirements for remote handling and in-situ calibration capabilities which are significantly beyond the provisions of existing tokamak experiments. Several of the more salient issues and concerns related to the design and operation of CIT diagnostics are detailed below.

\section{A. Tokamak Access}

Adequate access for viewing of the plasma is a universal problem with tokamak diagnostics. The configuration of the diagnostic port access for CIT is illustrated in Fig. 2. A total of 18 identical horizontal poris are provided with 10 ports allocated to plasma diagnostics. Each port is $0.37 \mathrm{~m}$ in width and $1.02 \mathrm{~m}$ in height with the distance from the port cover to the plasma edge being approximately $2.2 \mathrm{~m}$. Likewise, 18 pairs of top and bottom vertical ports are located at major radii corresponding to the center of the vacuum vessel and to the outboard half-radius of the plasma with diameters of $0.05 \mathrm{~m}$ and $0.10 \mathrm{~m}$, respectively. For diagnostics which must be located near the plasma boundary, for example wide-angle bolometer arrays, the lengthy reentrant port geometry creates difficulties both with regard to stable support of the diagnostic components as well as with 
remote-handling requirements, which will be discussed later.

The limited port access (CIT has fewer that one-half the ports available on TFTR, JET, and DIII-D, for example) restricts the number of diagnostics which can be deployed and, therefore, militates against the provision of redundant techniques for the determination of any given parameter. Such redundancy has proven valuable in tokamak experiments in the past. Spurious effects can occasionally render a single measurement unreliable, for example, in the case of a mildly non-thermal distribution function affecting the apparent electron temperature determined by cyclotron emission, or the presence of localized density feature (MARFE) disrupting the determination of integrated density by interferometry. In selecting the CIT diagnostic set, therefore, careful attention to the selection of systems which provide data and calibration cross-checking is required.

\section{B. Neutron and Gamma Radiation}

The neutron and gamma radiation environment for diagnostics on CIT is three or four orders of magnitude more severe than for TFTR (at $Q$ of 1 ). Selection of materials and components for diagnostic equipment requires careful evaluation of the effects of the radiation background on: 1) radiation-induced noise ${ }^{5}$ in detectors and the amount of shielding ${ }^{6}$ needed, 2) radiation damage and the need for hardened components? or capability for replacement by remote-handling methods, and 3) activation levels which could variously affect noise levels, calibration reliability, and remote-handling complexity.

For a 750-MW ignited pulse in CIT, typical flux levels at the vacuum vessel wall are $8 \times 10^{19} \mathrm{~m}^{-2} \mathrm{~s}^{-1}$ for neutrons and $2.7 \times 10^{19} \mathrm{~m}^{-2} \mathrm{~s}^{-1}$ for gamma rays. Integrated over a fraction of the CIT operating life, these flux levels raise concerns regarding the survivability of such mundane

components as quartz viewing windows for diagnostics. From a study by Primak, ${ }^{8}$ irradiation of vitreous silica and crystal quartz in a thermal nuclear reactor produced a progressive fractional change 
in the sample dimensions with increasing fluence over the range of neutron fluence expected for $\mathrm{CIT}$, as shown in Fig. 3. The dimensional changes in sapphire are considerably smaller. Neuton bombardment, however, is only one factor in the complex radiation exposure of diagnostic windows, which includes ultra-violet and soft $x$-ray absorption effects. Further study of these issues is needed.

\section{Tritium Exposure}

The tritium consumption in CIT for a single ignited discharge is estimated to be about $0.1-0.2$ grams or equivalently $1-2 \times 10^{3}$ Curies with the first-wall retention inventory building to 9.5 grams or $9.5 \times 10^{4}$ Curies. Although the impact of tritium exposure on the design, performance, and maintenance of materials and components is not fully understood at the present time, some areas of concern have been identified. The use of metal vacuum seals is mandatory in order to avoid atmospheric contamination due to permeation of tritum through elastomer seals. A degradation in the properties of insulators and lubricants, for example, vacuum pump oil, is anticipated, but adequate quantitative data to evaluate these effects ae scarce. Established procedures for the calibration of ion gauges in the presence of tritium do exist, but non-contact handling of such contaminated components is required.

Gas-phase molecular tritium decays into ${ }^{3} \mathrm{He}$ with the production of slow ions and the emission of electrons. The electrons have a broad energy spectrum with an end-point energy of 18.6 $\mathrm{keV}$ and an average energy of approximately $5.6 \mathrm{keV} .{ }^{9}$ The background noise level which is induces in exposed detectors that are sensitive to the tritium decay products is a concem. As an example, Figs. 4 and 5 show results from a study by Malinowski ${ }^{10}$ in which the background count rate induced in a chevron microchannel plate (MCP) detector was measured over a range of tritium exposure conditions. As seen in Fig. 4, the MCP count rate due to tritium exposure is directly 
proportional to the tritium pressure, a result also observed for channel electron multiplier (CEM) detectors in an earlier study by the same author. ${ }^{11}$ The magnitude of the background count rate was observed to depend on enviromental factors, such as the geometry of the detector enclosure and the presence of electromagnetic fields. This background noise is termed "reversible" since it vanishes when the tritium gas is removed. As shown in Fig. 5, an "irreversible" backgound count rate increases with cumulative tritium exposure is also observed and is attributed to OT hydroxyl formation by tritium exchange with the hydrogen hydroxyls present in MCP glasses. At low tritium exposures, an elevated noise level for the MCP detector was observed relative to expectations based on previous CEM data. Long-term bakeout of the MCP at temperatures up $10-150^{\circ} \mathrm{C}$ reduces the noise by a small factor $(\sim 3 \mathrm{x})$ but does not eliminate the irreversible count rate.

It is of interest to note that the pulse height spectrum for the "reversible" noise exhibits the bi-Gaussian shape which is characteristic of events initiated at the input surface of the MCP, whereas the "irreversible" noise exhibits an exponential shape which is the signature of counts originating within the bulk of the MCP chevron assembly.

\section{Remote Handling}

The ambient radiation levels due to machine activation following even a single, ignited D-T discharge in CIT require that replacement, calibration, and maintenance of diagnostic components located close to the tokamak be performed using remote-handling equipment. Modifications to existing systems or installation of new diagnosties require similar handling.

Two independent remote manipulator systems for CIT are under development at the Oak Ridge National Laboratory: 1) a pair of articulated boom manipulators for servicing first-wall or other components interior to the vacuum vessel, and 2) a boom-mounted manipulator with dual, real-time response, force-reflecting arms to service hardware outside the vessel mounted on the machine ports 
or located elsewhere in the test cell. Prototype tests on a simplified mock-up of the CIT machine have been performed at ORNL involving generic tasks such as the disassembly and reassembly of a metal-seal vacuum flange, as illustrated by the photograph shown in Fig. 6 . These tests clearly demonstrated the enormity and complexity of providing a realistic remote-handling capability for CIT. To expedite remote handling activities and simplify the requirements for specialized end-effector tooling, certain features must be incorporated into components at the initial design stage, such as alignment guides, lifting tabs, radiation-compatible electrical and fluid connectors, retaining clips, and module sizing to comply with the manipulator lifting capacity. The most severe requirement, however, lies in providing adequate access and working space for the manipulator to operate on a given component. A full-sized mock-sp of the CIT machine core which includes every component or obstacle impacting the remote-handling functions must be constructed in order to verify handling capability prior to performing the task in the activated environment of the machine itself.

\section{Discussion of Selected CIT Diagnostics}

The design effort for CIT diagnostics is presently in the conceptual phase with activity being focissed on the selection of a viable diagnostic set, the development of preliminary mechanical designs, ${ }^{12-13}$ and the establishment of $R \& D$ programs both to support this process and to develop new techniques which are essential for measurement of collective alpha-particle effects. In order to select a preliminary set of diagnostics for which detailed analysis and evaluation will be performed, a survey was made of both the well-established methods currently in use on most tokamaks as well as more recently developed techniques offering potential advantages for CIT, such as LIDAR Thomson scattering ${ }^{14}$ and millimeter-wave reflectrometry. ${ }^{15}$ Factors considered in the selection process included the capability to perform measurements over the full range of CIT plasma parameters, tokamak accessiblilty requirements, radiation and tritium sensitivity, and the viability of 
remote-handling techniques. SeveraI standard diagnostics were summarily eliminated, such as charge exchange neurral particle analysis because of opacity effects at high plasma densities and conventional soft $\mathrm{x}$-ray wave techniques for MHD activity measurements due to detector failure in the hostile neutron and gamma radiation environment.

Table II presents a listing of the preferred measurement techniques for different plasma parameters with some comments about specific diagnostic requirements and concerns. Within the scope of this paper, it is possible to discuss only a subset of these diagnostics in further detail.

\section{A. Electron Temperature and Density}

Forward Thomson scattering is under investigation to provide full spatial distributions of the electron density and electron temperatures up to $T_{e}(0) \sim 20 \mathrm{keV}$. A modified port arrangement is required in order to accommodate the tangential, midplane access needed for the laser beam and collection optics, as illustrated in Fig. 7. Detailed aspects of the laser dump, stable alignment of reflective optics within the reentrant por, the location and effects of radiation on windows, and interferences with other systems require further study before adopting this approach. The simple radial access employed by the LIDAR technique now operating at JET ${ }^{14}$ offers an atractive alternative and is being investigated. This technique achieves spatial resolution by time-of-flight measurement of backscattered light from the laser pulse as it traverses the plasma. Because of the small size of CIT compared with JET, it is expected that shorter laser pulse widths and faster time-of-flight electronics are necessary in order to provide measurements with the desired spatial resolution of $5 \mathrm{~cm}$ or better.

Michelson and grating polychromator electron cyclotron emission diagnostics ${ }^{16,17}$ are productively employed on several of the major tokamak experiments for electron temperature profile measurements. The fact that sensitive components can be located outside the test cell with only a 
relatively simple, radiation-rugged waveguide interface at the vacuum vessel port makes these techniques attractive for implementation on CIT, as illustrated by the conceptual layout shown in Fig. 8. In principle, the possibility exists of combining both the Michelson and polychromator spectrometers on a single waveguide to the machine. Aspects which require further study include possible degradation of the spatial resolution due to Doppler broadening effects at the high electron temperatures in CIT, absorption and harmonic vierlap interferences, and absolute calibration of the instruments using methods which are compatible with remote-handling facilities.

Other techniques under investigation for the measurement of electron density include infrared interferometry in the 10-119 $\mu \mathrm{m}$ wavelength range and millimeter-wave reflectrometry in the 30-300

$\mathrm{GHz}$ frequency range. Infrared interferometry using dual wavelengths ${ }^{18}$ to compensate for machine vibrations might be used for feedback control of the plasma density as well as for profile measurements. However, the provision of suitable multichord viewing access to enable Abel unfolding of the line-integrated interferometer data to derive density profiles is an unresolved problem at the present time. Millimeter-wave reflectrometry, on the other hand, requires only midplane access. Since the technique is based on the reflection of electromagnetic waves from the plasma cut-off layer, measurements are restricted to the outer half of peaked density profiles and to the edge region of hollow density profiles.

\section{B. Ion Temperature}

Charge exchange recombination spectroscopy (CXRS) has been used in conjunction with auxiliary heating or dedicated diagnostic neutral bears: to measure profiles of the ion temperature and toroidal rotation velocity in tokamak experiments such as TFTR, JET, JT-60, and DIII-D. Assuming that adequate concentrations of impurity species, such as carbon, exist in CIT, a diagnostic neutral beam of $\sim 500 \mathrm{keV} / 1 \mathrm{~A}$ He or $\mathrm{H}$ particles is needed in order to provide adequate doping levels. At 
the high electron densities anticipated for CIT, $10 \%$ or less of the neutral beam survives being ionized during transit to the plasma core. Furthermore, the extraneous radiation due to bremsstrahlung is expected to produce low signal-to-noise ratios which will require phase-locked measurements with modulation of the beam source.

$X$-ray crystal spectrosccpy has also been successfully employed for ion temperature measurements on the major tokamaks and is planned for CIT. At the high electron temperatures projected ( $\mathrm{T}_{e} \sim 20 \mathrm{keV}$ ), injection of krypton may be needed in onder to realize helium- or hydrogenlike ionization levels in the plasma core and hence obtain line-integral measurements which are centrally weighted.

Although epithermal and spectroscopic neutron measurements are central to the ineasurement of plasma bum conditions, they are included as ion temperature diagnostics due to the expectation that ICRH heating at the high electron densities in CIT will yield near-Maxwellian ion energy distributions which are amenable to interpretation as temperature data. A conceptual layout of a multichannel collimator array to obtain spatially resolved measurements is shown in Fig. 9, which also illustrates the scheme for remote-handling removal of the detector system. This array is being analyzed for the effect of neutrons scattered from the core of the tokamak.

\section{Impurities/Radiated Power}

These measurements embody two of the most difficult interface problems which are encountelid for CIT diagnostics. Impurity measurements require a vacuum line-of-sight access to the tokamak which leads to problems of tritium contanination of the appa:atus and to high neutron and gamma radiation levels as a :esult of streaming through the necessary penetration to the tokamak. Additional shielding around this diagnostic is needed to alleviate elevation of the neutron and gamma radiation levels elsewhere in the facility, as shown in Fig. 10. 
Bolometer diagnostics for measurement of the radiated power in CIT require radial viewing access for multichannel, wide-angle radial arrays as well as tangential sightlines. ${ }^{19}$ In order to achieve this, radiation-resistant optics or detectors must be mounted near the plasma boundary via deep reentrant horizontal ports, as discussed earlier. Also, compensation for nuclear heating of the detectors is needed.

\section{Alpha Particles}

The mission of CIT is the study of collective alpha particle effects in an ignited D-T plasma which includes heating, confinement scaling, instabilities, fueling, beta limits, and alpha-ash or impurity accumulation. For diagnostic purposes, the approaches to alpha measurements ${ }^{20}$ are divided into three categories: 1) Escaping alphas, which are detected using probes located near the plasma periphery ${ }^{21}$ for energies typically in the range of $0.5-3.5 \mathrm{MeV}$, 2) Fast-confined alphas, which require measurements internal to the plasma at energies in the range of $0.5-3.5 \mathrm{MeV}$, for which a viable technique has not been identified but is the subject of several $R \& D$ projects to be discussed, and 3) Slow-confined alphas in the energy range of 0.01-0.5 MeV, which are substantially thermalized and amenable to measurement using charge exchange recombination spectroscopy in conjunction with a diagnostic neutral beam, as discussed earlier.

The study and development of diagnostics for measurement of fast-confined alpha particles is being supported by funding from the Department of Energy-Division of Applied Physics and other sources. Projects in progress include: 1) studies of collective Thomson scattering by $\mathrm{CO}_{2}$ laser $^{22}$ and millimeter-wave gyrotron 23 techniques, 2) photon annd neutral particle reactions with ablating carbon pellets, ${ }^{24}$ neutral beam probes, ${ }^{25}$ ion cyclotion spectroscopy, ${ }^{26}$ and spectroscopic ${ }^{27}$ and imaging 28 measurements of the $16 \mathrm{MeV}$ prompt gamma emission from $\mathrm{D}-{ }^{3} \mathrm{He}$ and D-T reactions. 


\section{Concluding Remarks}

The development of the diagnostics for the Compact Ignition Tokamak is in the preliminary phase. Assessment of certain diagnostics for use on CIT awaits results of R\&D projects, such as for fast-confined alpha particle diagnostics. Some techniques which offer advantages for application to CIT such as LIDAR Thomson scattering and millimeter-wave spectrometry will be certified in the course of experiments on other tokamaks. In addition, the CIT diagnostics group has identified other R\&D support programs which cover: 1) radiation qualification of detectors and materials, 2) radiation qualification of optical components, 3) diagnostic component development, 4) magnetic diagnostics (primarily for feedback control), 5) diagnostic vacuum equipment requirements, and 6) RF noise shielding. With the exception of the alpha diagnostics program which is actively funded, the remaining $R \& D$ programs are in the start-up phase at the present time.

\section{Acknowledgment}

This work has been supported by U.S. Department of Energy Contract No. DE-AC02-76-CHO-3073. 


\section{References}

1 T.E. Shannon, in Proceedings of the IEEE 12th Symposium on Fusion Engineering, Monterey, CA, October 1987, (IEEE, Piscataway, NJ, 1988), Vol.1. pp. 256-259.

2 J.R. Wilson, in Proceedings of the Course and Workshop on Applications of RF Waves to Tokamak Plasmas, Varenna, Italy, 1985, (Monotypia Franchi, Perugia, Italy, 1985), Vol. I, pp. 184-186.

3 J.J. Yugo, P.L. Goranson, D.W. Swain, F.W. Baity, and R.Vesey, in Proceedings of the IEEE 12th Symposium on Fusion Engineering, Monterey, CA, October 1987, (IEEE, Piscataway, NJ, 1988), Vol.2, pp. 1192-1195.

4 S.L. Liew and L.P. Ku, in Proceedings of the 12th Symposium on Fusion Engineering, Monterey, CA. October 1987, (IEEE, Piscataway, NJ, 1988), Vol. 2, pp. 844-847.

5 S. S. Medley and R. Persing, Rev. Sci. Instrum. 52, 1463-1468(1981).

6 A.L. Roquemore, S.S. Medley, and S.D. Scott, presented at the 7th Topical Conference on High Temperature Plasma Diagnostics, (Napa, CA, March 1988). To be published in Rev. Sci. Instrum., August 1988.

7 J.F. Baur, B.A. Engholm, M.P. Hacker, I. Maya, P.H. Miller, W.E. Toffolo, and S.S. Wojtowicz, "Radiation Hardening of Diagnostics for Fusion Reactors," General Atomic Report GA-A 16614/UC-20 (December, 1981). 
8 W.Primak, "Radiation Damage in Diagnostic Window Materials for the TFTR," Argonne National Laboratory Report ANL/FPP/TM-146 (July, 1981).

J. Law, Phy. Rev. D Vol. 7, 3314-3317 (1973).

10 M.E. Malinowski, "The Response of a Microchannel Plate to Low Pressure Gaseous Tritium," Sandia National Laboratories Report SAND82-8831 (November, 1982).

11 M.E. Malinowski, "Tritium Caused Background Currents in Electron Multipliers," Sandia National Laboratories Report SAND79-8218 (May 1979).

12 L.E. Dudek, J. Lowrance, K.M. Young, and L.P. Ku, in Proceedings of the IEEE 12th Symposium on Fusion Engineering, CA, October 1987, (IEEE, Piscataway, NJ, 1988), Vol_.2 pp. 1492-1495.

13 J.L. Lowrance, L.E. Dudek, K.M. Young, and L.P. Ku, in Proceedings of the IEEE 12th Symposium on Fusion Engneering, CA, October 1987, (IEEE, Piscataway, NJ, 1988), Vol. 2. pp. 1548-1550.

14 H. Salzmann, J. Bundgaard. A. Gadd, C. Gowers, K.B. Hansen, K. Hirsch, P. Nielsen, C. Schrodter, and K. Weisberg, presented at the $7 \mathrm{th}$ Topical Conference on High Temperature Plasma Diagnostics, (Napa, CA, March 1988). To be published in Rev. Sci. Instrum., August 1988.

15 A. E. Costley, in Proceedings of the Course and Workshop on Basic and Advanced Fusion Plasma Diagnostic Techniques, (Varenna, Italy 1986).

16 F.J. Stauffer, D.A. Boyd, R.C. Cutler, M. Diesso, M.P. McCarthy, J. Montague, and RE. Rocco, "Broadband Measurements of Electron Cyclotron Etrission in TFTR Using a Quasi-Optical Light Collection System and a Polarizing Michelson Interferometer", Princeton Plasma Physics Laboratory Report, PPPL-2508 (April 1988). 
17 A. Cavallo, M.P. McCarthy, and R. Cutler, Rev. Sci. Instrum. (in press).

18 C.H. Ma, D.P. Hutchinson, and K.L. Vander Sluis, presented at the 7th Topical Conference on High Temperature Plasma Diagnostics, (Napa, CA, March 1988). To be published in Rev. Sci.Instrum., August 1988.

19 J. Schivell, presented at the 7th Topical Conference on High Temperature Plasma Diagnostics, (Napa, CA, March 1988). To be published in Rev. Sci.Instrum., August 1988.

20 S. J. Zweben, Rev. Sci. Instrum. 57, 1723-1728(1986).

21 S. J. Zweben, Rev. Sci. Instrum.57, 1774-1776(1986).

22 R.K. Richards, C.A. Bennett, L. Fletcher, H.T. Hunter, and D.P. Hutchinson, presented at the 7 th Topical Conference on High Temperature Plasma Diagnostics, (Napa, CA, March 1988). To be published in Rev. Sci. Instrum., August 1988.

23 P.P. Woskov, J.S. Machuzak, D.R. Cohn, N.L. Bretz, P.C. Efthimion, and J. L. Doane, presented at the 7th Topical Conference on High Temperature Plasma Diagnostics, (Napa, CA, March 1988). To be published in Rev. Sci.Instrum., August 1988.

R. K. Fisher, J. S. Leffler, A. M. Howald, and P. B. Parks. Fusion Technology (in press).

J.W. Stearns, A. S. Schlachter, and W.S. Cooper, presented at the 7th Topical Conference on High Temperature Plasma Diagnostics, (Napa, CA, March 1988). To be published in Rev. Sci.Instrum., August 1988.

K.G. Moses, J.L. Sperling, J.C. Dooling, and C. Chu, presented at the 7th Topical Conference on High Temperature Plasma Diagnostics, (Napa, CA, March 1988). To be published in Rev. Sci.Instrum., August 1988. 
S. S. Medley, Rev. Sci. Instrum. 56, 975-977(1985).

R. D. Petrasso, C. Fiore, and Chi-Kang Li, presented at the 7 th Topical Conference on High Temperature Plasma Diagnostics, (Napa, CA, March 1988). To be published in Rev. Sci. Instrum., August 1988. 


\section{Table I}

\section{Selected CIT Parameters}

Major radius

$2.10 \mathrm{~m}$

Minor radius

$0.65 \mathrm{~m}$

Elongation

2.0

Triangularity

$0.3-0.5$

Plasma current

$11 \mathrm{MA}$

Flux swing

$51 \mathrm{~V}-\mathrm{s}$

Toroidal field

$10 \mathrm{~T}$

MHD safety factor (minimum)

3.2

Toroidal field flat-top time

$5.0 \mathrm{~s}$

Current ramp-up time

$6.0 \mathrm{~s}$

RF heating baseline (ICRH @ 95 MHz)

$10 \mathrm{MW}$

RF heating full compliment (ICRH/ECH)

$20 \mathrm{MW}$

Vessel bakeout/operating temperature

$150^{\circ} \mathrm{C}-350^{\circ} \mathrm{C}$

Number of full-field pulses

3000

Number of $70 \%$ field pulses

30,000

$\mathrm{LN}_{2}$ cool-down consumption

280,000 liters

$\mathrm{LN}_{2}$ re-cool consumption

40,000 liters

Full field re-cool time

Electron density: $n_{e}(0)$

Electron ternperature: $\mathrm{T}_{\mathrm{e}}(0)$

60 minutes

$<1 \times 10^{21} \mathrm{~m}^{-3}$

$<20 \mathrm{keV}$

Ion temperanure: $T_{e}(0)$

$<30 \mathrm{keV}$

Zeff

1.5

Confinement time for ignition: $\tau_{\mathrm{E}}$

- flat profile

-- peaked profile

$-650 \mathrm{~ms}$

$\sim 450 \mathrm{~ms}$

Fusion power

$750 \mathrm{MW}$

Alpha power

Wall neutron flux @550 MW

$150 \mathrm{MW}$

Wall gamma flux @ 550 MW

Wall neutron power loading @ 550 MW

$\sim 8 \times 10^{19} \mathrm{~m}^{-2} \mathrm{~s}^{-1}$

$-2.7 \times 10^{19} \mathrm{~m}^{-2} \mathrm{~s}^{-1}$

$\sim 9 \mathrm{MW} / \mathrm{m}^{2}$ 
Table U

CIT Preliminary Diagnostic List

\section{Electron Density}

Thomson Scattering ( $10-20^{\circ}$ forward or $180^{\circ}$ LDAR system)

Infrared Interferometer (10-119 um wavelength range, two color)

Millimeter-wave Interferometer ( $30-300 \mathrm{GHz} @ 100 \mathrm{~mW}$, outer profile)

\section{Electron Temperature}

Thomson Scattering (see Electron Densiry)

Electron Cyclotron Emission (Michelson and/or grating polychromator)

\section{Ion Temperature}

CX Recombination Spectroscopy ( $\sim 500 \mathrm{kV} / 1 \mathrm{~A} \mathrm{H}$ or He diagnostic beam)

$\mathrm{X}$-ray Crystal Spectrometer (3-channel, krypton doping may be needed)

Neutron Spectrometer (high energy resolution, time-of-flight method)

Neutron Collimator (10-channel radial array, $\sim 10 \mathrm{~ms}$ resolution)

Epichermal Neutron Detectors (wide dynamic range fission detectors)

\section{Impurities/Radiated Power}

Visible Bremsstrahlung Arrays (interference filters, radial viewing)

VUV and X-ray Spectroscopy (O, C, and metal lines, LSM/crystal optics)

Bolometers (concerns about viewing access and detector selection)

\section{Magnetic Properties}

Rogowski Loops (two toroidal locations, one redundant)

Flux/Voltage Loops (minimum of 20 toroidal loops, $~ 10$ ms response)

Diamagnetic Loops (two toroidal locations, one redundant)

Locked-mode Coils (minimum of four toroidal locations) 


\section{Wave Activity}

Mimov Loops (poloidal and toroidal arrays inside the vacuum vessel)

FIR Graning Polychromator ( 20-channel radial array)

Neutron Fluctuation Detectors(fast scinillators in collimator array)

Millimeter-wave Scattering (study alpha particle instabilities)

\section{Alpha Particles}

Escaping Alphas (energy / pitch-angle resolving probes near first wall)

Fast-Confined Alphas (concepts being investigated in R\&D programs)

Slow-Confined Alphas (CX recombination spectroscopy for $E<400 \mathrm{keV}$ )

\section{Edge/Divertor Phenomena}

Plasma TV/Infrared TV (monitor first-wall/diveror conditons)

Visible Filter Scopes ( $\mathrm{H}_{\alpha}$ and $\mathrm{C}$ filters, monitor divertor performance)

Probes/Thermocouples (monitor power deposition on limiters/divertor)

\section{ICRF Monitoring}

$16 \mathrm{MeV} \gamma$-Spectroscopy/Imaging (NE226 and gas Cherenkov detectors) 


\section{Figure Captions}

1. Elevation view of the CIT core assembly.

2. Isometric view of the CIT vacuum vessel illustrating the layout of the horizontal and vertical port access.

3. Fractional dimensional change of fused and crystal quartz windows with integrated neutron fluence exposures in a thermonuclear reactor.

4. Reversible tritium-induced noise count-rate in a chevron microchannel plate detector as a function of tritium pressure.

5. Irreversible tritium-induced noise count rate in a chevron microchannel place detector as a function of total tritium exposure.

6. Photograph of the M-2 remote manipulator at ORNL during a prototype test involving disassembly of a vacuum flange on a mock-up of the CIT machine.

7. Concept for a forward Thomson scattering system on CIT illustrating: a) a plan view of the tangential, midplane geometry and necessary port arrangements, and b) an elevation view of the collection optics port showing a possible arrangement for window shielding.

8. Concepnual layout of a grating polychromator diagnostic on CIT.

9. Conceptual layout of a multichannel neutron collimator diagnostic on CIT with an illustration of the removal sequence for a detector module compatible with remote-handling requirements.

10. Conceptual layout of a UV spectrometer on CIT showing the recovery 
shielding required for diagnostics having a line-of-sight vacuum interface with the tokamak. 
\#89x0447

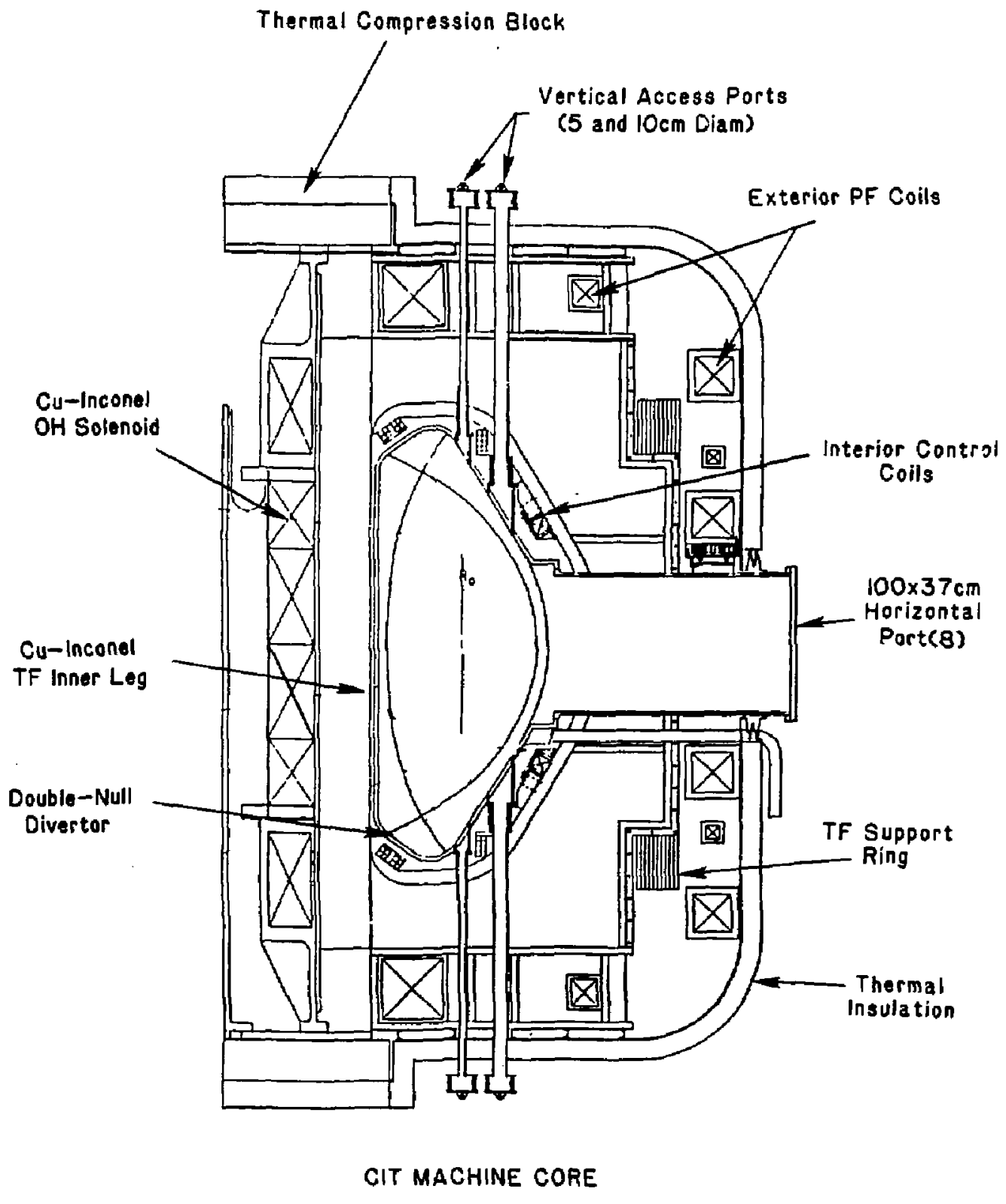

Fig. 1 


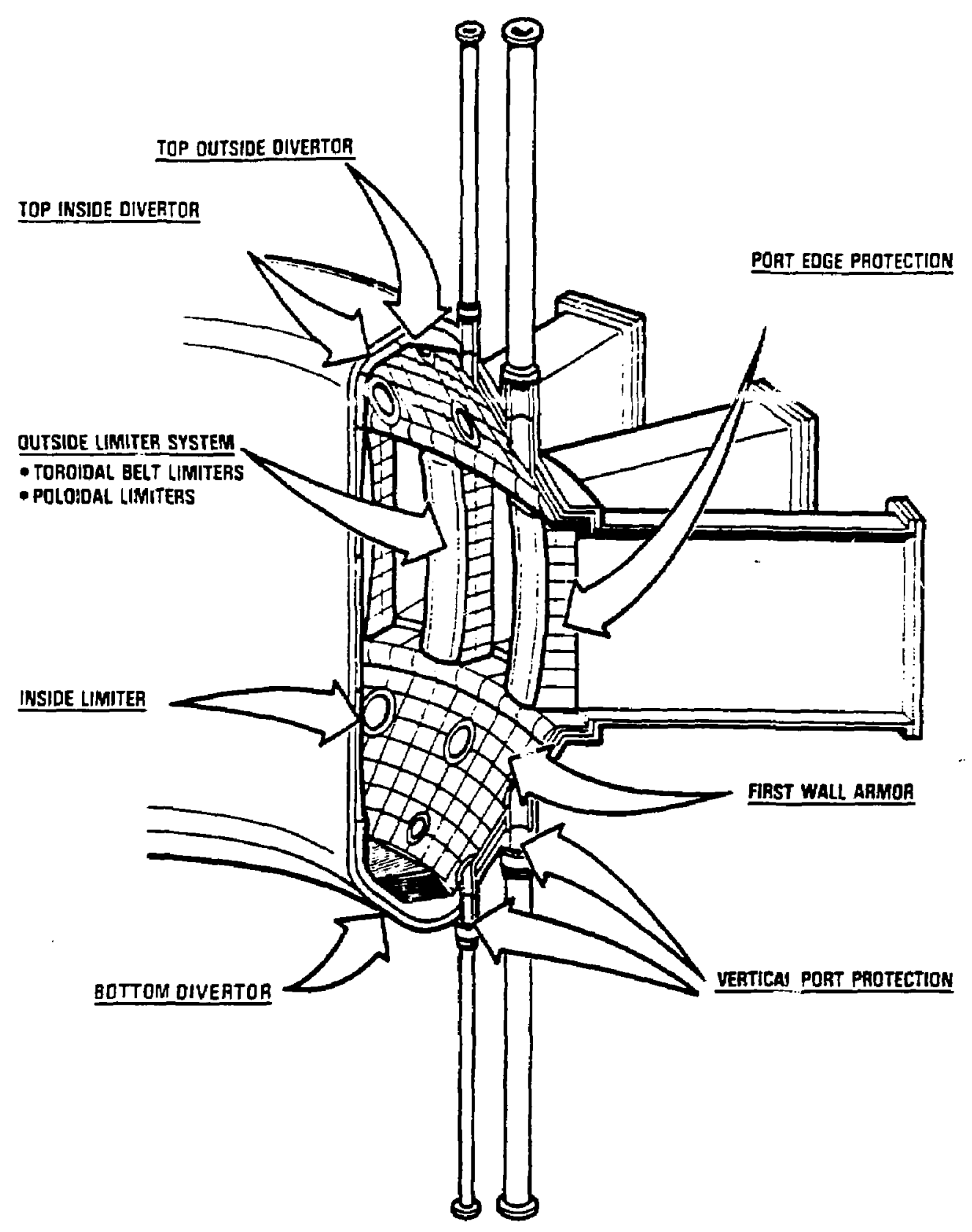

Fig. 2 


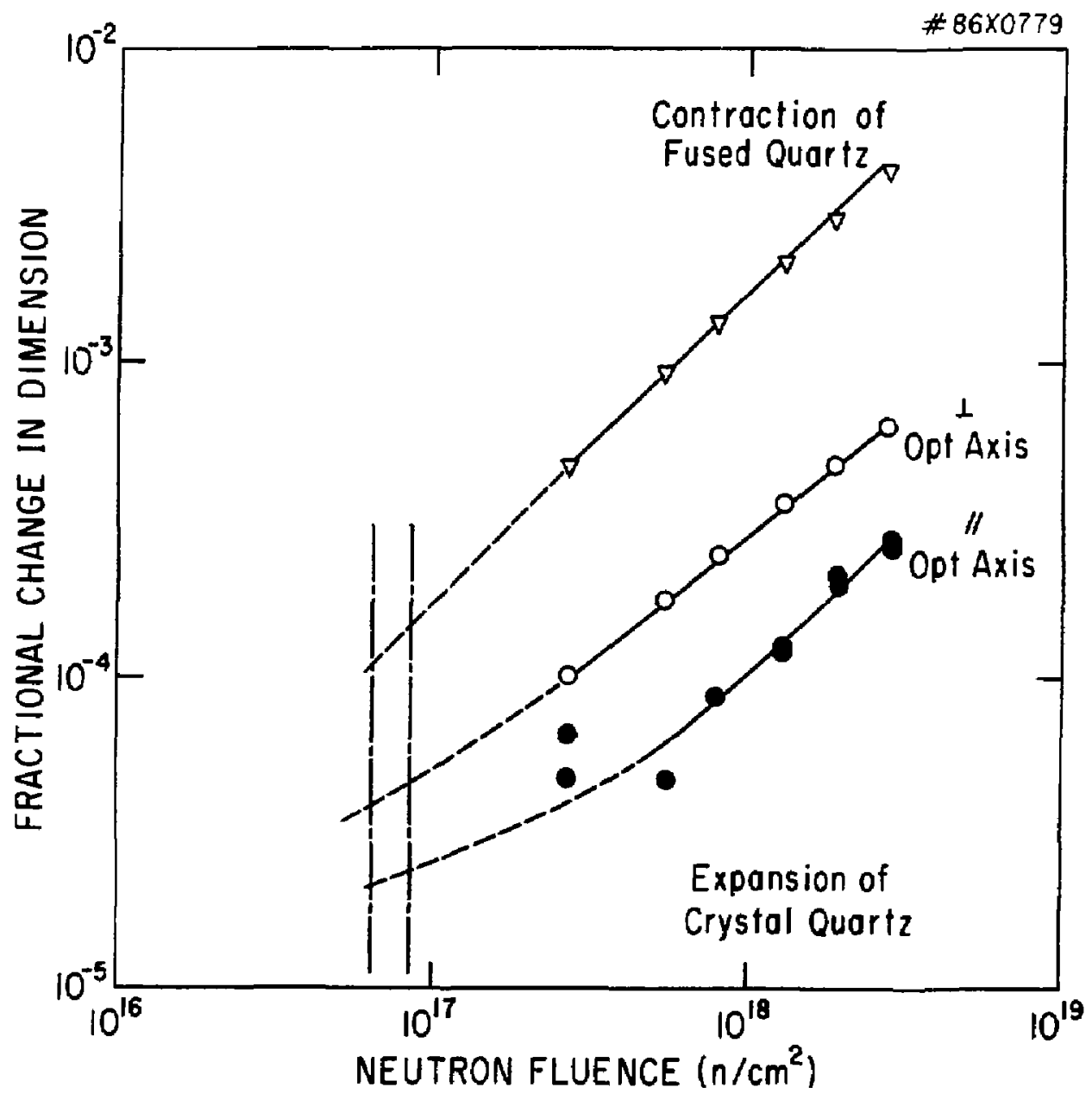

Fig. 3 


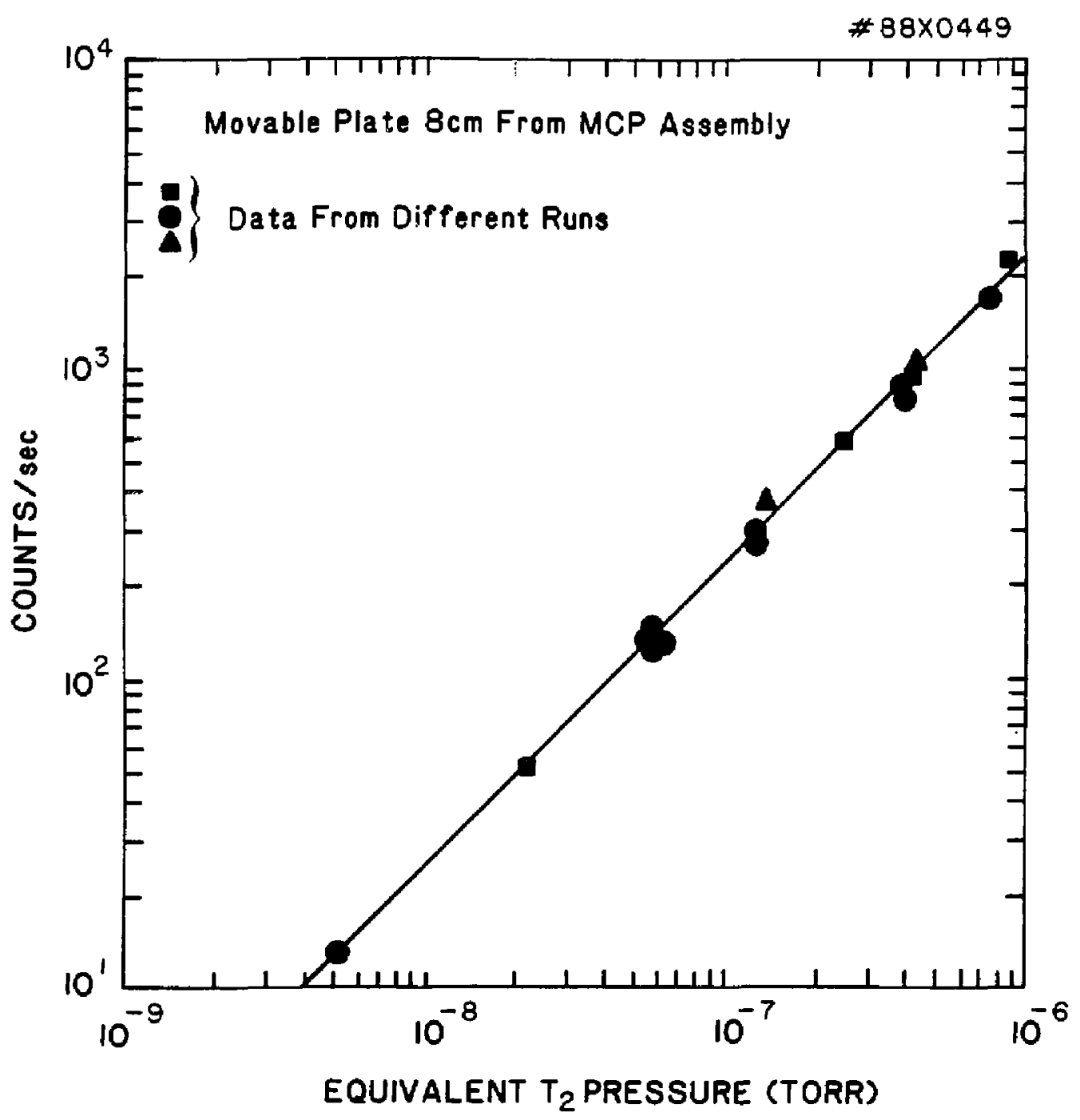

Fig. 4 


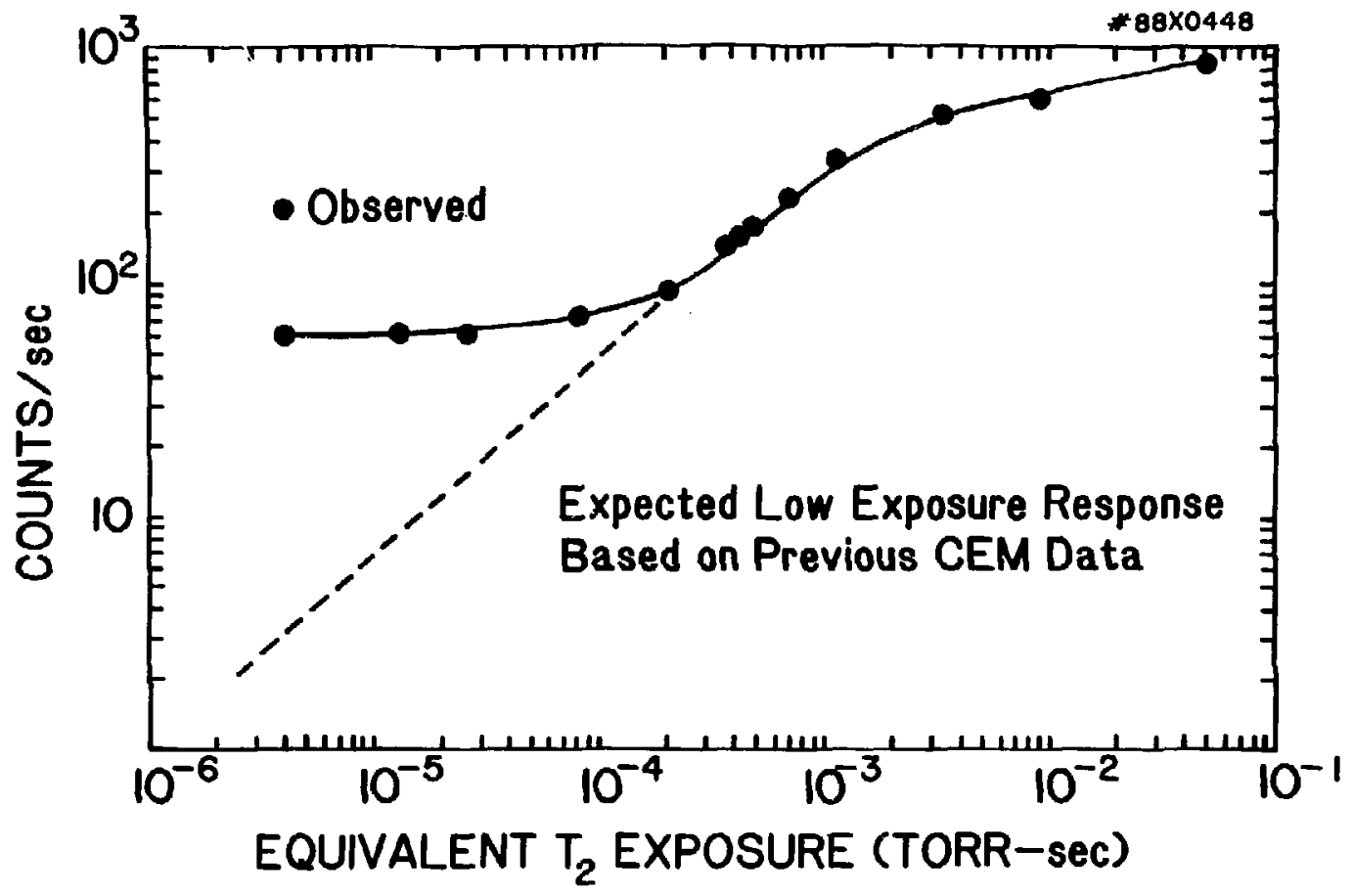

Fig. 5 


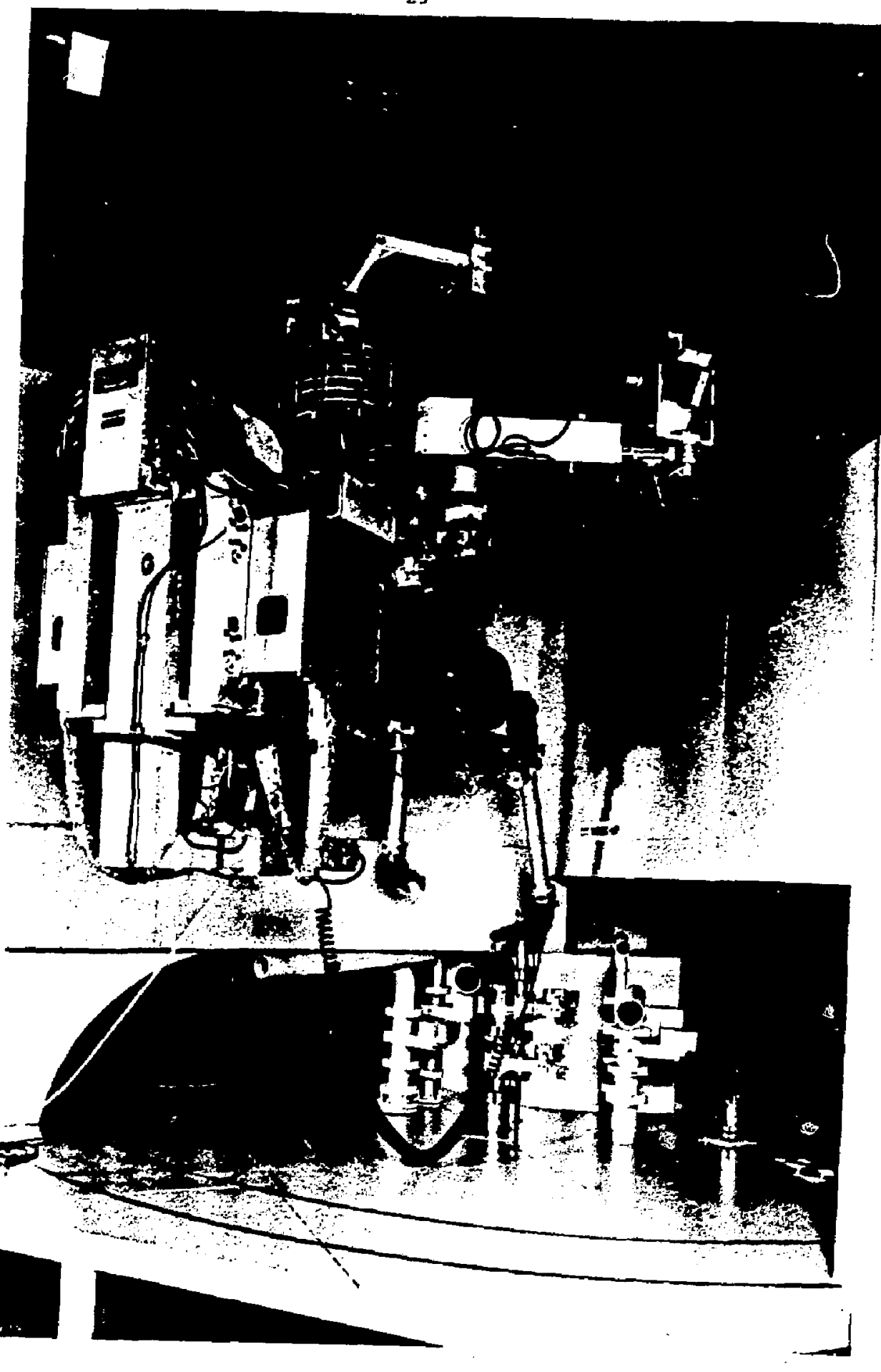

Fig. 6 
\#86x0768
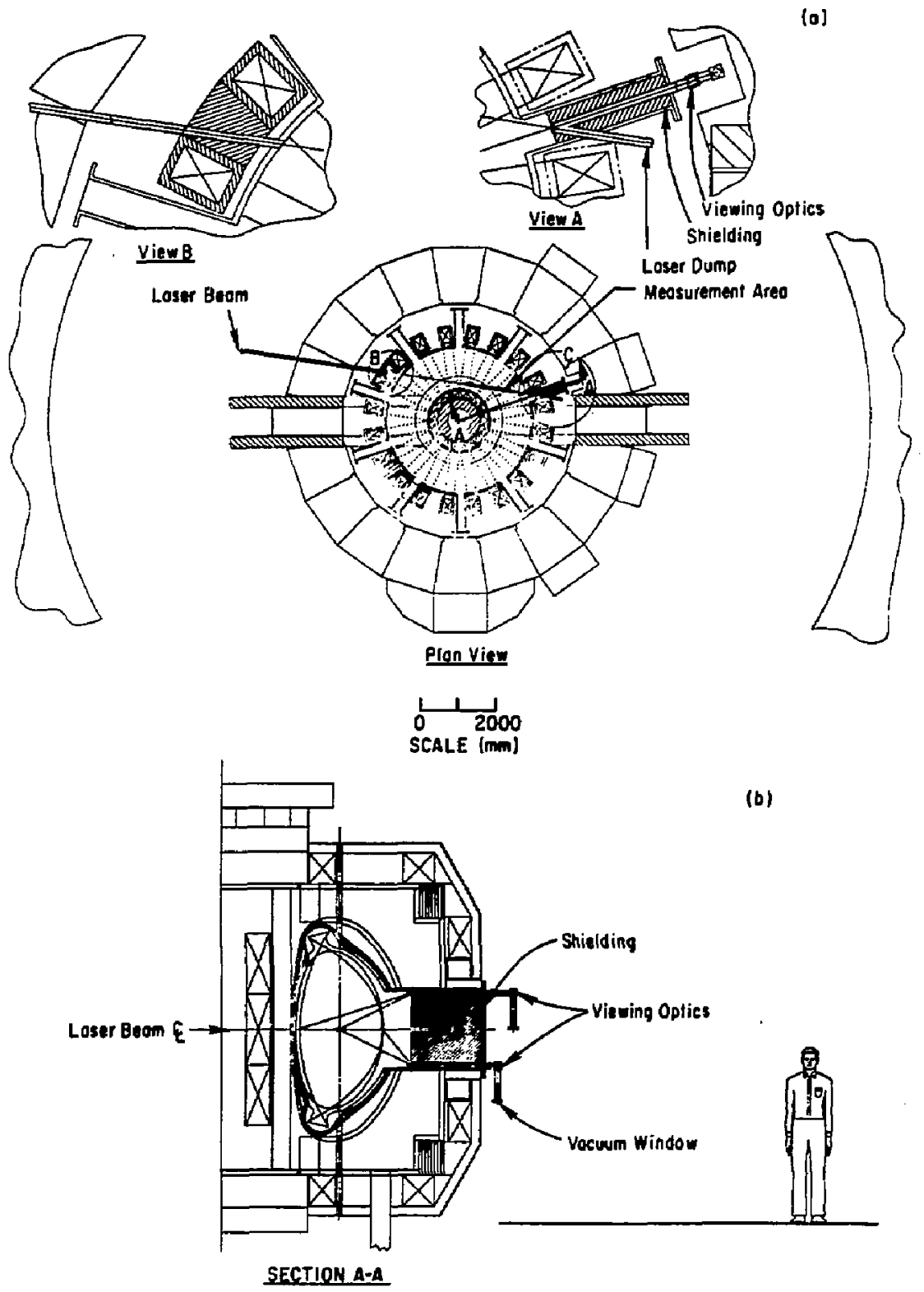

$\frac{1}{0} \frac{1000}{2000}$

Fig. 7 


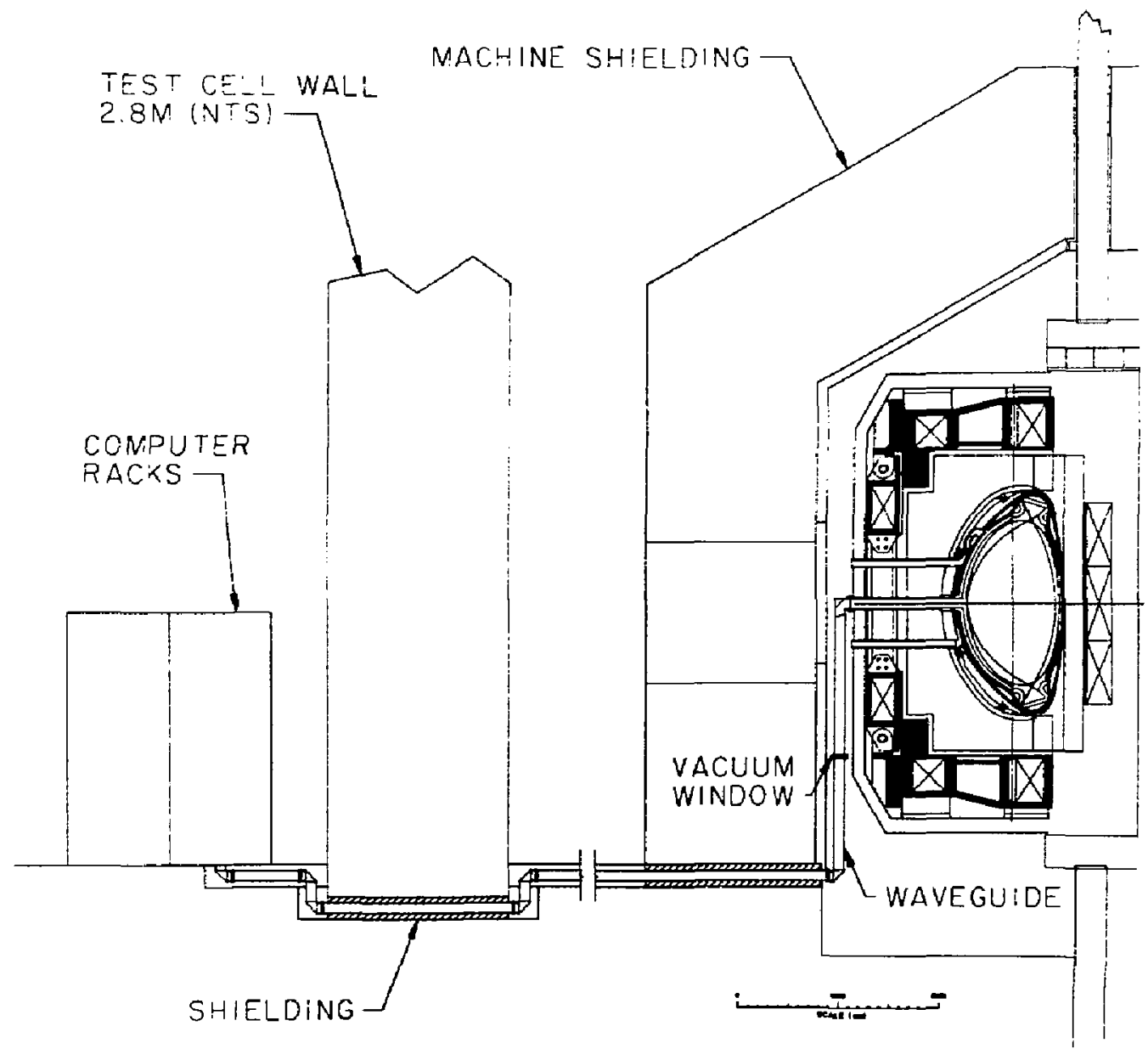

Fig. 8 


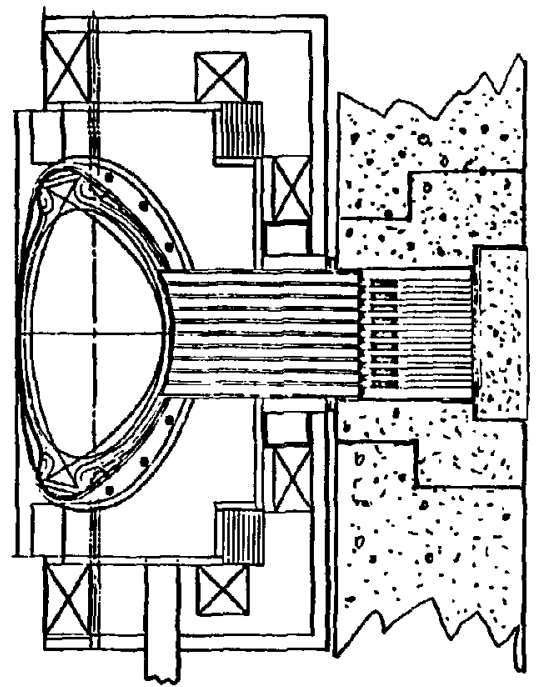

Neutron Collimotor

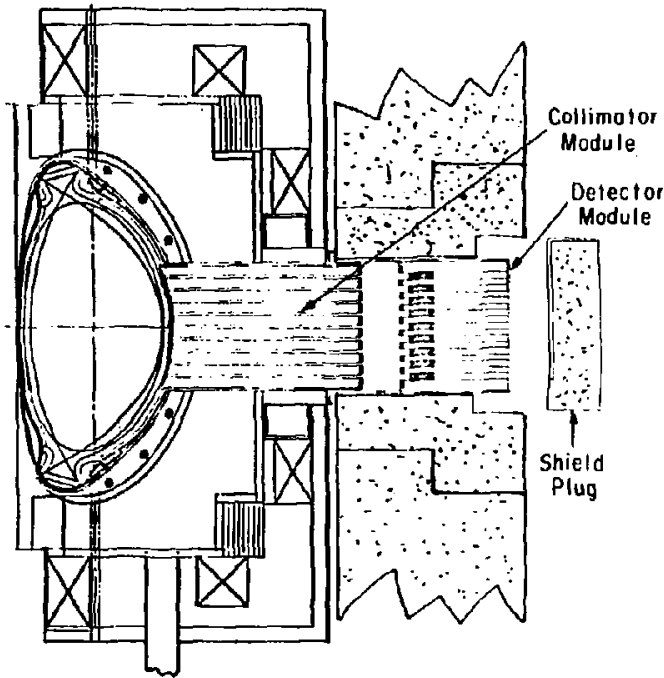

Removal Sequence for Defector Module 


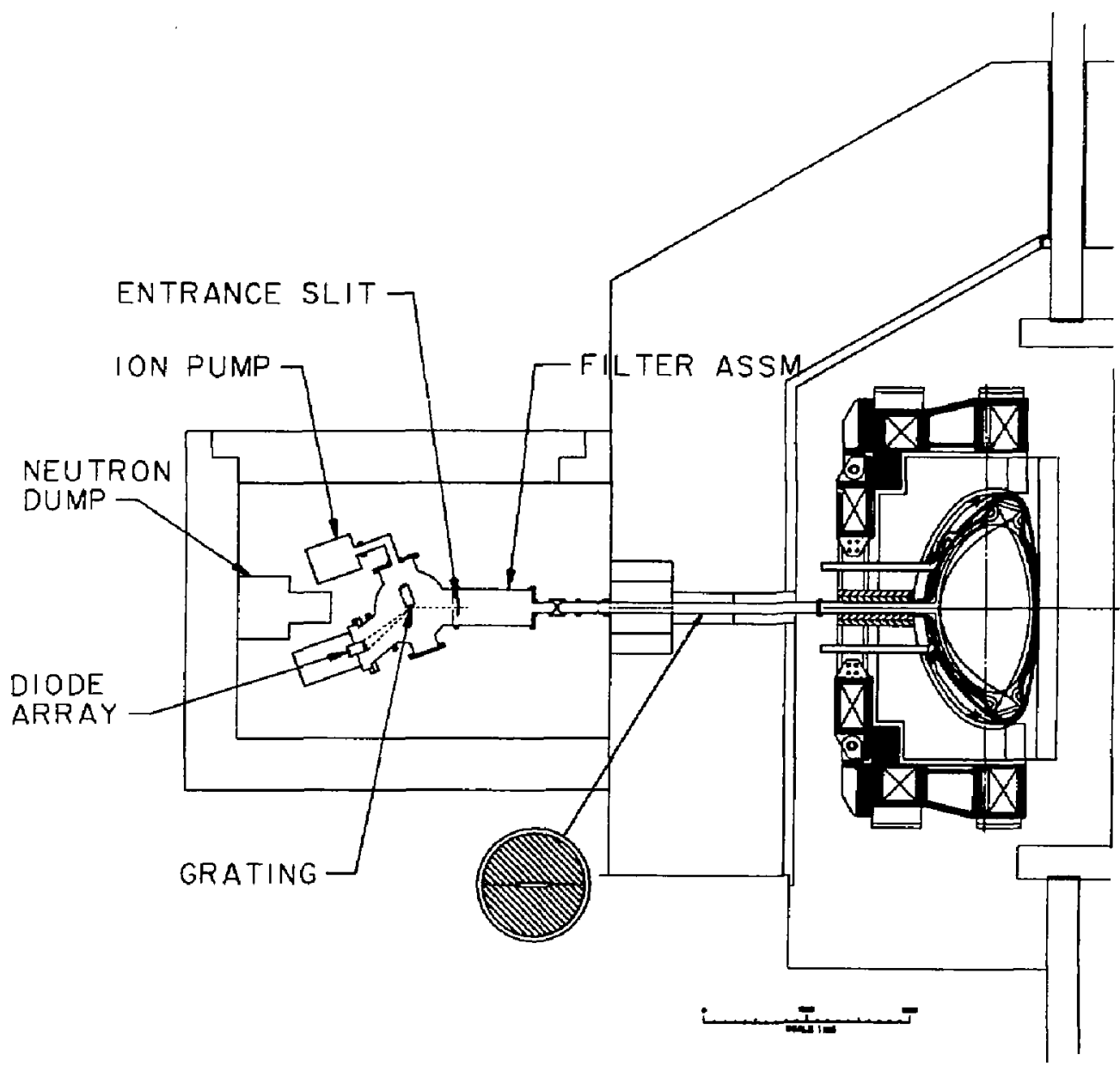

Fig. 10 
Or. Frank J. Paoloni, Univ of Wollongong, AUSTRALIA Prof. M.H. Brennan, Univ Sydmey, AUSTRALIA

Plasma Research Lab.. Australian Not. Univ., AUSTRALIA

Prof. I,R. Jones, Flinders Univ... AUSTRALIA

Prof. F. Cap, inst Theo Phys, Austria

Prof. M. Heindler, Institut fur Theoretische Physik, AUSTRIA

M. Coossens, Astronomisch Instituut, BELGIUM

Ecole Royale Militaire, Lab de Phys Plasias, Belgium

Comission-European, Dg-XII Fusion Prog, BELGIUM

Prof. R. Boucique, Laboratorium voor Natuurkunde, BELGILA

Dr. P.H. Sakanaka, Instituto FIsica, BRAZIL

Instituto De Pasquisas Espaciasi-INPE, BRAZIL

Documants Otfica, Atomle Energy of Canada Linitod, Canada

Dr. M.P. Bachynski, MPS Technologies, InC., CANADA

Or. H.M. Skarsgard, University of Saskatchewan, CANuOA

Dr. H. Barnard, Univarsity of British Columola, CANAOA

Prof. J, Teichmann, Iniv. of Montraal, CAMAOA

Prot. S.R. Sraenlvasan, University of Calgary, CANADA

Prof. Tudor W. Johnston, INRS-Energie, CANADA

Dr. C.R. Jomes, Univ. of Alberta, CANAOA

Dr. Pater Lukac, Xomenskeho Univ, CZECHOSlovakIA

The Librarion, Culham Laboratory, ENGLANO

The Librarian, Rutherford Appleton Laboratory, ENGLAND

Mrs. S.A. Hutehinson, JET Library, ENGLANo

C. Mouttet, Lab. de Physique des Mil ieux Ion is es, FrancE

J. Radat, CEN/CADARACHE - Bat 506, FRANCE

Univ. of loannina, Library of Physics Dept. GREECE

Dr. Ton Mual, Academy bioliographic Ser., hONG KONG

Preprint Library, Hungarian Academy of Sciences, HJNGARY

Dr. B. Dasgupta, Saha Inst of Nucl. Phys., IROIA

Dr. P. Kaw, Institute for PI asma Rosearch, INDIA

Dr. Philip Rosenau, Israel Inst. Tech, ISRAEL

Librarian, Int'l Ctr Theo Phys, ITALY

Prof. G. Rostagni, Univ Di Padova, ITALY

Miss Clolia oe Pala, Assoc EuRATom-EnEA, ITALy

Biblioteca, Instituto dl fisica del Plasma, ITALY

Dr. H, Yamato, Foshiba Res \& Dov. JAPAN

Prof. I, Kawakami, Atomic Enargy Ras. Institute, JAPAN

Prof. Kyoji Nishikawa, Univ of Hiroshime. JAPAN

Direc. Dept. Large Tokasak Ras. JAERI, JAPAN

Prof. Sotoshi Itoh, Kyushu University, JAPAN

Research info Center, Nagoya Univarsity. JAPAN

Prof. S. Tonaks, Kyoto University, JAPAN

Library, Kyoto University, JAPAN

Prof. Nobuyuki Inoue, University of Tokyo, JAPAN

5. Mor $i$, JAERI, JAPAN

Librarian, Kores Advanced Energy Res. Institute, KOREA

Prof. D.1. Choi, Adv, Inst Sei \$ Teeh, KOREA

Prof. B.5. Li ley, University of Waikato, NEW ZEALANO

Institute of Plasma Physics, PECPLE'S REPUalic of CHINA

Librarian, Instituto of Phys., PEOPLE'S REPUELIC OF CHINA

Library, Tsing Hua University, PEOPLE'S REPUBLIC of CHINA
Z. Li, Southwast Inst. Physics, PEOPLE'S REPUBLIC OF CHINA Prof. J.A.C. Cabral, Inst Superior Tecnico, PORTugal Dr. Octavian Petrus, AL I CUZA University, ROMANIA Dr. Johan de Villiers, Fusion Studies, AEC, SO AFRICA Prof. M.A. Helloarg, University of Natal, SO AFRICA

C.I.E.M.A.T., Fusion Div. Library, SPAIN

Dr. Lennart Stentlo, University of LMEA, SWEDEN

Library, Royal Inst Tech, SWEDEN

Prof. Hans Wilhelnson, Chalmers Univ Tech, SWEDEN

Centre Phys des Plasnas, Ecole Polytech Fed, SWITZERLAND

BIbllotheak, Fom-Inst Voor PIasma-fysica, THE NETHERLANDS

Dr. D.D. Ryutov, Siberian Acod Sci, USSR

Dr. G.A. Eliseev, Kurchatar Institute, USSR

Dr. V.A. Glukhikh, Inst Electrophysical Apparatus, USSR

Or. V.T. Tolok, Inst. Phys. Tech, USSR

Dr. L.M. Kovrlzhnykh, Institute Gen. Physics, USSR

Nuclear Ras. Establishment, Julich Ltd., W. GERMANY

Blbl iothak, Inst. Fur Plasmatorschung, W. GEPAANY

Dr. K. Sct:indler, Ruhr Univorsitat Bochum, W. GERAANY

ASDEX Roading Ron, IPP/Mox-Planck-Institut fur

Plasmaphysik, H. GERMANY

Librarian, Max-Pianck Institut, W. GERMANY

Prof. R.K. Janev, Inst Phys, YugosLavia 